\title{
EMPREGO DA SECA-AERAÇÃO PARA SOJA ARMAZENADA A GRANEL
}

\author{
Maxwel Rodrigues Nascimento ${ }^{1}$ \\ Mario Euclides Pechara da Costa Jaeggi ${ }^{2}$ \\ Julio Cesar Gradice Saluci ${ }^{3}$ \\ Israel Martins Pereira ${ }^{4}$ \\ Rebyson Bissaco Guidinelle ${ }^{5}$ \\ Alex Justino Zacarias ${ }^{6}$ \\ Rogério Rangel Rodrigues ${ }^{7}$ \\ Samuel Ferreira da Silva ${ }^{8}$ \\ Luís César da Silva ${ }^{9}$
}

Resumo: Uma das soluções para diminuir os gargalos na recepção das unidades armazenadoras de grãos é a adoção da operação de seca-aeração. Esta operação consiste em retirar dos secadores grãos de 1 a 3 pontos percentuais de teor de água acima do recomendável para armazenagem e transferir para um silo, onde permanece por um período de 4 a 12 horas de descanso. Em seguida, são acionados os ventiladores para insuflar o ar ambiente, sob condições psicrométricas ideais, por um período que varia de 10 a 20 horas, com a finalidade de resfriar e retirar o excesso de água da massa de grãos até que o teor de água atinja $13 \%$, ideal para o armazenamento. Foram levantados dados meteorológicos dos principais municípios produtores de soja da região Centro-Oeste do Brasil. Com esses dados foi possível determinar o número médio de horas ideias por dia para essa operação por ocasião do período da colheita. Diante dos dados essa operação é viável para região.

Palavras-chave: Condição psicrométrica; Teor de água; Unidades armazenadoras.

\footnotetext{
${ }^{1}$ Mestrado em Produção Vegetal/Universidade Estadual Norte Fluminense Darcy Ribeiro, Brasil. E-mail: maxwel.rn88@gmail.com.

2 Mestrado em Produção Vegetal/Universidade Estadual Norte Fluminense Darcy Ribeiro, Brasil. E-mail: mariopechara@hotmail.com.

3 Teconologia em Cafeicultura/Instituto Federal do Espírito Santo campus Alegre, Brasil. E-mail: juliosaluci@gmail.com.

4 Teconologia em Cafeicultura/Instituto Federal do Espírito Santo campus Alegre, Brasil. E-mail: israelmartins80@gmail.com.

5 Teconologia em Cafeicultura/Instituto Federal do Espírito Santo campus Alegre, Brasil. E-mail: rebysonguidinelle@gmail.com.

6 Teconologia em Cafeicultura/Instituto Federal do Espírito Santo campus Alegre, Brasil. E-mail: alexjustino12@gmail.com.

7 Doutorado em Engenharia Agrícola/Universidade Federal de Lavras, Brasil. E-mail: rogeriorr7@hotmail.com.

8 Doutorado em Produção Vegetal/Universidade Federal do Espírito Santo, Brasil. E-mail: samuelfd.silva@yahoo.com.br.

${ }^{9}$ Professor, Universidade Federal do Espírito Santo, Brasil. E-mail: silvaluisc@yahoo.com.
} 